\title{
速応性交流サーボモータとしての誘導機の 過渡現象解析と磁界加速法制御
}

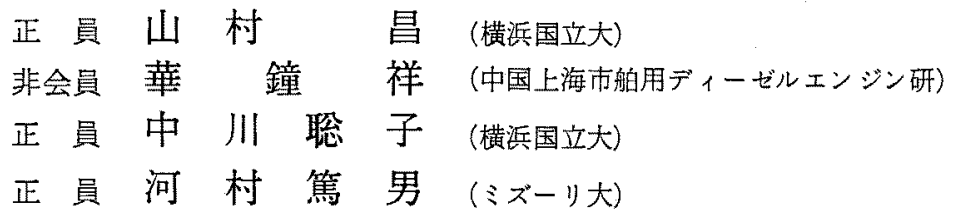

\section{1. 緒言}

三相誘導電動機の制卸技術が進歩して，これまで直 流機が用いられていた分野に進出しているが，その制 御理論としてはべクトル制御理論に㮩ることが多い。 ベクトル制御は酉ドイッで発案されたもので，トルク 発生の機構を直流機传類似させて，磁束と二次起磁力 との直交性を基本としている。三相二相の座標变換を 行なって等洒二相機によって磁束と二次起磁力との直 交性を説明する。トルク指令に忘じて等洒二相機の一 次電流を定めて，てれを三相座標に逆変換して，その 一次電流を定める。ベクトル制御は元来電流形制御で あって，座標变換のためにその理諭も制御回路す複雑 になり過ぎると考える。ベクトル制御の他の問題の一 つは，電磁気的過渡現票に十分な考虑力゙払われていな いことである。

誘導機の過渡現象は複雑であって解析が難かしい。 てれまでの過渡現象の解析では三相二相の座標変換を して得られる等価二相機によっていた(1)(7)。しかし，

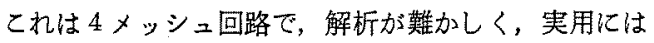
便利でない。二相機の $d, q$ 軸座標を更に瞬時対称座 標法によって変数変換をする手法が猪狩 ${ }^{(2)}$, Adkin 氏

Analysis of Transient Phenomena and Field Accelaration Control of Induction Motor as A-C Servomotor of Quick Response. By Sakae Yamamura, Member (Yokohama National University, Faculty of Engineering), Hua Zhong Xiang, Non-member (Marine Diesel Engine Research Institute, Shanghai, China), Satoko Nakagawa, Member (Yokohama National University, Faculty of Engineering) \& Atsuo Kawamura, Member (UniveIsity of Missouri-Columbia, Electrical Engineering Department),

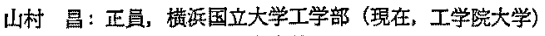

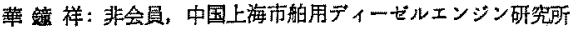
中川聁子: 正員, 横捠国立大学工学部

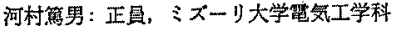

ら(3)の著書にああるが，2 段の変数変換をする結果， 元の変数による現象を見るのが困難になり，この解析 法によってサーボモータの制御理論を考元るのは極め てむずかしい。

筆者らは(4)，先に誘導機の過渡現象を場理論によっ て解析して，その減衰時定数が大きくて，過渡現象の 発生を防がなり机は，応答の速い制御は不可能である ことを示し，制御ステップごとに一次電流のつながり を適切にすることによって，過渡現象の発生を防ぐこ とを基本とする制御法を提案して，乙れを磁界加速制 御と名付けた。ギャップ中の回転磁界が全然崩れない で，その速度だけを加堿してトルクを制御するという 趣旨である。

磁界加速法制御では，誘導機の等価回路による一次 電流あるいは一次電圧の制御演算が基礎になる。篗者 らはさきの論文で(5)，等価回路として T 型, T-I 型, T-II 型， L 型の四つの等価回路を導いて，これらの 等伍回路江対忍して聯界加速法制御の制御特性がごの ようになるかを明らかにした。

筆者らは苜，更に，誘導機の過渡現象について電気 回路理論的な解析を進めて，座標変換を行なうことな く，過渡現象をす表現できる等価回路に到達した。こ れは三相機の定常状態任対する従来の等価回路が拡張 された形のむのであるが，理論上，また実用上の意義 は大きいむのと考える。すなわち，誘導機の過渡現象 の解が，電流形制御についてむ電王形制御についてす 容易に求められ，その解仕誘導機の速応制御の基礎と なるものと考える。本論文においてはこの過渡現象に む適用できる搪張された等洒回路を用いて，磁界加速 法制御につき更に重要ないくつかの結論を与えるむの である。 


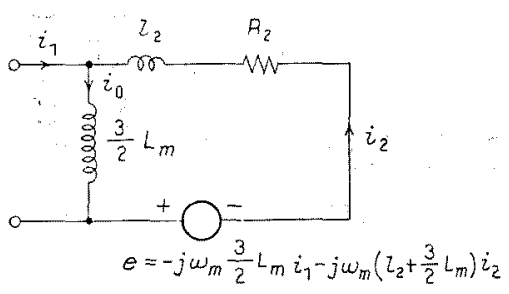

図 1 電流形制御の過渡等価回路

Fig. 1. Transient equivalent circuit for current-type control.

\section{2. 電流形制御の解析}

筆者らは先の論文 ${ }^{(6)}$ において，電流形制御をされる 誘導機の過渡現象をむ表方すことのできる過渡等価回 路は图1で与えられることを示した。電流形制御にお いて一次電流を $i_{1}$ ，励磁電流を $i 0$ とすると，図1の 等価回路より下記の回路方程式が得られる。

$$
\begin{aligned}
& R_{2} i_{0}+\left(l_{2}+\frac{3}{2} L_{m}\right)\left(p-j \omega_{m}\right) i_{0} \\
& =\left\{R_{2}+l_{2}\left(p-j \omega_{m}\right)\right\} i_{1} \ldots \ldots . .
\end{aligned}
$$

ここに， $\omega_{m}$ は回転角速度で，他の記号については四 1 を参照のとと。とのラプラス変換は

$$
\begin{aligned}
R_{2} I_{0}(\mathrm{~S})+\left(l_{2}+\frac{3}{2} L_{m}\right)\left(\mathrm{S} I_{0}(\mathrm{~S})\right. & \\
& \left.-I_{00}-j \omega_{m} I_{0}(\mathrm{~S})\right\} \\
= & \left\{R_{2}+l_{2}\left(\mathrm{~S}-j \omega_{m}\right)\right\} I_{1}(\mathrm{~S}) .
\end{aligned}
$$

となる。こてに，Sはラプラス演算子，I00 は励磁電 流の初期值である。(2)式より下式が得られる。

$$
\begin{aligned}
I_{0}(\mathrm{~S})= & \frac{R_{2}+l_{2}\left(\mathrm{~S}-j \omega_{m}\right)}{R_{2}+\left(l_{2}+\frac{3}{2} L_{m}\right)\left(\mathrm{S}-j \omega_{m}\right)} I_{1}(\mathrm{~S}) \\
& +\frac{\frac{3}{2} L_{m}+l_{2}}{R_{2}+\left(l_{2}+\frac{3}{2} L_{m}\right)\left(\mathrm{S}-j \omega_{m}\right)} I_{00}
\end{aligned}
$$

この式の特性根は一つで

$$
\mathrm{S}=-\frac{R_{2}}{l_{2}+\frac{3}{2} L_{m}}+j \omega_{m}=\delta=-\lambda+j \omega_{m}
$$

であって，てれを $\delta ま た ゙ は ~ 一 \lambda+j \omega_{m}$ と圆く。電流 形制御においては一次電流 $i_{1}$ 於駆動源であって，そ の複素表現およびラプラス変換は下記となる。

$$
i_{1}=\sqrt{2} I_{1} e^{j \omega t}, \quad I_{1}(\mathrm{~S})=V \overline{2} I_{1} \frac{1}{\mathrm{~s}-j \omega}
$$

これを(3)式仁代入して下式を得る。

$$
\begin{aligned}
I_{0}(\mathrm{~S})= & \frac{1}{l_{2}+\frac{3}{2} L_{m}} \frac{R_{2}+l_{2}\left(\mathrm{~S}-j \omega_{m}\right)}{\mathrm{S}-\delta} \frac{\sqrt{2} I_{1}}{\mathrm{~S}-j \omega} \\
& +\frac{I_{00}}{\mathrm{~S}-\delta} \ldots \ldots \ldots \ldots \ldots \ldots \ldots \ldots \ldots \ldots \ldots \ldots \ldots \ldots \ldots \ldots
\end{aligned}
$$

との式のラプラス逆変換として, 励磁電流识 $(t)$ は下 式となる。

$$
\begin{aligned}
i_{0}(t)= & \frac{R_{2}+j s \omega l_{2}}{R_{2}+j s \omega\left(l_{2}+\frac{3}{2} L_{m}\right)} \sqrt{2} I_{1} e^{j \omega t} \\
& -\frac{R_{2}}{R_{2}+j s \omega\left(l_{2}+\frac{3}{2} L_{m}\right)} \frac{\frac{3}{2} L_{m}}{l_{2}+\frac{3}{2} L_{m}} \\
& \times \sqrt{2} I_{1} e^{\delta t}+I_{00} e^{\delta t} \ldots \ldots \ldots \ldots(7)
\end{aligned}
$$

ことに, $s$ はず゙り $\left[s=\left(\omega-\omega_{m}\right) / \omega\right)$ であって, 上式 の第 1 項は定常解，第 2 , 第 3 項は之むに隇衰過渡項 である。従って過渡現象を発生しない制御条件は下記 で与えられる。

$$
\begin{aligned}
& \frac{R_{2}}{R_{2}+j s \omega\left(l_{2}+\frac{3}{2} L_{m}\right)} \frac{\frac{3}{2} L_{m}}{l_{2}+\frac{3}{2} L_{m}} \bar{V} I_{1} \\
& =I_{00} \ldots \ldots \ldots \ldots \ldots \ldots \ldots \ldots \ldots \ldots \ldots(
\end{aligned}
$$

ここに，I00 は励磁電流の初期值 (複素表現)である。 （8）式によって II を定めれば，過渡現象の発生しな い制御が可能になる。電流形制御の磁界加速法におい て，（8)式化よって一次電流を定めて，トルクの制御 を行なえば，図2のような時間幄れのないトルク応答 が得られるととになる。このことは，筆者らの先の馀 文 ${ }^{(4)}$ に和いて既に指摘したところであって，磁界加速 法の大きな特長である。誘導機は理諭上で, 正流機よ りむ優れた応答を持ち得るサーボモータである。この ような認識はべクトル制御理論に叔いては矢けていた とてろであり，過渡現象への理解を欠いていたからで あると考える。

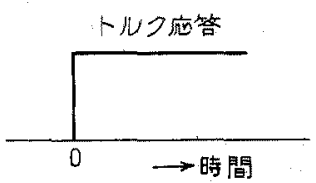

因 2 トルク制御のステップ応答 Fig. 2. Step response of torque for current-type control. 


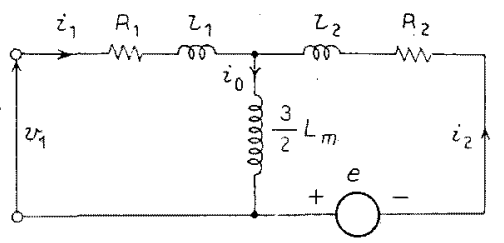

目 3 対称 $T$ 型過渡等価回路

Fig. 3. Symmetrical $T$ type transient equivalent circuit.

\section{3. 各種の過渡等価回路}

筆者引は先の論文 ${ }^{(6)}$ に扎いて，一次端子電圧を入力 とする過渡等価回路を与えた。罒了にをれを示してあ るが，乙机は対称 $\mathrm{T}$ 型回路過渡現象俍対しても成り 立つむのであるので, 対称 $\mathrm{T}$ 型過渡等価回路と呼ぶて とにする。普通の等価回路估定常状態のみを扱うすの であるが，て机汶対称 T 型，非対称 T-I 型，非対称 T-II 型， L 型などがあるととを，先の論文 ${ }^{(5)}$ で示し た。過渡現象に対しては図 3 の対称下型のみ導いた のであるが，定常等価回路について行なった之同様な 手法によって，過渡等価回路に対しても，各種の型を 導くことができる。

図3 の対称 $\mathrm{T}$ 型過渡等価回路の回路方程式は下記で 与えられる。

$$
\begin{aligned}
& {\left[\begin{array}{c}
v_{1} \\
0
\end{array}\right]=\left[\begin{array}{c}
R_{1}+l_{1} p+\frac{3}{2} L_{m p} \\
\frac{3}{2} L_{m}\left(p-j \omega_{m}\right)
\end{array} *\right.} \\
& \text { * } \left.\begin{array}{c}
\frac{3}{2} L_{m} p \\
R_{2}+\left(l_{2}+\frac{3}{2} L_{m}\right)\left(p-j \omega_{m}\right)
\end{array}\right]\left[\begin{array}{l}
i_{1} \\
i_{2}
\end{array}\right]
\end{aligned}
$$

電流を次式で变換する。

$$
\left[\begin{array}{l}
i_{1} \\
i_{2}
\end{array}\right]=\left[\begin{array}{ll}
1 & 0 \\
0 & \alpha
\end{array}\right]\left[\begin{array}{c}
i_{2} \\
i_{2}{ }^{\prime}
\end{array}\right]=C\left[\begin{array}{c}
i_{1} \\
i_{2}{ }^{\prime}
\end{array}\right] .
$$

$\alpha$ 任任意定数で， $C$ は㚆換行列を表わす。(9)式の1 ンピーダンス行列 $[Z]$ を $C_{t}[Z] C$ によって変換して 下式を得る。

$$
\left.\begin{array}{rl}
{\left[\begin{array}{l}
v_{1} \\
0
\end{array}\right]=\left[\begin{array}{l}
R_{1}+l_{1} p+\frac{3}{2} L_{m} p \\
\frac{3}{2} L_{m} \alpha\left(p-j \omega_{m}\right)
\end{array}\right.} \\
\\
\quad R_{2} \alpha^{2}+\alpha^{2}\left(l_{2}+\frac{3}{2} L_{m} \alpha p\right)\left(p-j \omega_{m}\right)
\end{array}\right]
$$

昭 $58-7$

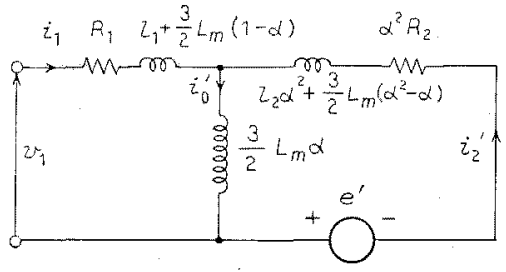

国 4 一般過洨等価回路

Fig. 4. Generalized transient equivalent circuit.

$$
\times\left[\begin{array}{c}
i_{1} \\
i_{2}^{\prime}
\end{array}\right]
$$

この式に対応する等価回路は图 4 となる。この四で $e^{r}$ は速度起笔力で，下式で与えられる。

$$
\begin{aligned}
e^{\prime}= & -j \omega_{m} \frac{3}{2} L_{m} \alpha i_{1}-j \omega_{m} \\
& \times\left(l_{2} \alpha^{2}+\frac{3}{2} L_{m} \alpha^{2}\right) i_{2}^{\prime}
\end{aligned}
$$

この回路には任意定数 $\alpha$ が含まれているので，過渡 等洒回路も無限に多数あるととになる。图 4 の等価回 路を一般過渡等価回路と呼ふとととする。

任意定数 $\alpha$ を 1 と定めると，図 4 の回路は图 3 の 対称 T型過淮等伍回路となる。図4の回路で $\alpha$ を下記 のように定めると，

$$
\alpha=\frac{\frac{3}{2} L_{m}}{l_{2}+\frac{3}{2} L_{m}}
$$

二次漏れインダクタンスが雾となって，図5の回路之 なる。これを非対称 T-I 型過渡等価回路と时年こと 上する。一次漏机インダクタンスを零とするためには $\alpha$ を下記のように定めればよい。このとき等価回路

$$
\alpha=\frac{l_{1}+\frac{3}{2} L_{m}}{\frac{3}{2} L_{m}}
$$

は㘡6となる。これを非対称 T-II 過渡等価回路と呼

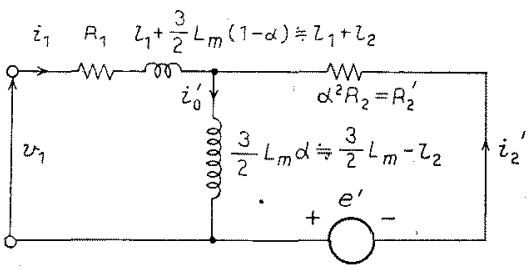

图 5 非対称 T-I 型過滛等牺回路

Fig. 5. Unsymmetrical T-I type transient equivalent circuit. 


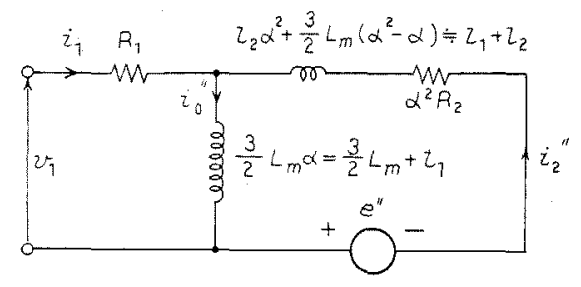

图 6 非対称 T-II 型過渡等価回路

Fig. 6. Unsymmetrical T-II type transient equivalent circuit.

30

図3 〜図6の等価回路は一次端子で見るとき，全く 等価であって，差はない。従って一次端子で見た過渡 現象についても，定常状龍についてむで四つの回路に おいて差はない。しかしながら二次側関する現象に ついては，四つの回路は見期け上異なるむのとなる。

図3 の回路による電流形制御の解は (7) 式であった が，乙れに対応する図4の一般過源等価回路の解は次 式で与えられる。

$$
\begin{aligned}
i_{0^{\prime}}(t)= & \frac{R_{2} \alpha+j s \omega\left\{\alpha l_{2}+\frac{3}{2} L_{m}(\alpha-1)\right\}}{\alpha\left\{R_{2}+j s \omega\left(l_{2}+\frac{3}{2} L_{m}\right)\right\}} \\
& \times \sqrt{2} I_{1} e^{j \omega t} \\
& -\frac{R_{2}}{\alpha\left\{R_{2}+j s \omega\left(l_{2}+\frac{3}{2} L_{m}\right)\right\}} \\
& \times \frac{\frac{3}{2} L_{m}}{l_{2}+\frac{3}{2} L_{m}} \sqrt{2} I_{1} e^{\delta t}+I_{00} e^{\delta t}
\end{aligned}
$$

この式より過渡現象を発生しない条件を求める之，

$$
\begin{aligned}
& \frac{R_{2}}{\alpha\left\{R_{2}+j s \omega\left(l_{2}+\frac{3}{2} L_{m}\right)\right\}} \frac{\frac{3}{2} L_{m}}{l_{2}+\frac{3}{2} L_{m}} \sqrt{2} I_{1} \\
& =I_{00} \text {. }
\end{aligned}
$$

を得る。この式は一般的に, どの過渡等価回路にお いても，励磁電流一定の制御の各ステップのつなぎ が，過渡現象を伴なわないで可能であることを示すす のである。

(15)，(16)式で $\alpha=1$ とすると，それぞれ(7)，(8) 式と一致する。 $\alpha$ を(13)式のように定めると，(15)式 は下式となり。

$$
i_{0}(t)=\frac{R_{2}}{R_{2}+j s \omega\left(l_{2}+\frac{3}{2} L_{m}\right)} \sqrt{2} I_{1} e^{j \omega t}
$$

$$
\begin{aligned}
& -\frac{R_{2}}{R_{2}+j s \omega\left(l_{2}+\frac{3}{2} L_{m}\right)} \sqrt{2} I_{1} e^{\delta t} \\
& +I_{00} e^{\delta t} \ldots \ldots \ldots \ldots \ldots \ldots \ldots \ldots \ldots \ldots \ldots \ldots \ldots \ldots \ldots \ldots
\end{aligned}
$$

(16) 式の過渡現象を発生しない条件式は

$$
\frac{R_{2}}{R_{2}+j s \omega\left(l_{2}+\frac{3}{2} L_{m}\right)} \sqrt{2} I_{1}=I_{00}
$$

となる。(17) 式では過渡項 (第 2 項) と定常項 (第 1 項) の係数の部分が一致することが注目される。このよう に T-I 型等価回路では， $t=0$ で定常項之過渡項とが 一致するので，過渡現象の発生を防ぐための制御演算 が単純になる(付録I 参照)。

\section{4. 電圧形制御}

$\mathrm{T}$ 型(図3)，T-I 型(図5)，T-II 型(図6)のい⿺ れの過渡等価回路によってあ電王形制御の解析を行な うととが可能であるが，てれらは 2 メッシュ回路であ るので，一般には過渡項が二つ発生して，二つの過渡 項を発生しないように制御することは困難である。こ れに反して電流形制御に上机ば，過渡項の発生を防い で，時間迤れのないトルク制御ができることを，上に 説明した。

しかしながら電流形制御化も問題がある。一次電流 I1の制御倍鿁差があると，発生トルクに誤差が生じる ばかりでなく，過渡現象を発生して，トルク制御佂䰠 れを生じる(第 5 章参照)。先の論文 ${ }^{(6)}$ に示したよう に，電流形制御の過渡現象の減衰時定数は非常に大き いので，とのトルク制御の遅れむ大きい。一次電流の 制御が理論通りに行なえない理由が幾つかある。回転 子の温度加上ると，二次抵抗 $R_{2}$ 少大きくなって，電 流制御任誤差を生じる。一次側侟れインダクタンス があって，理諭通りの一次電流の制御を不可能とす る。このような理由で，電流形制御は理論通りに実行 することは難かしく，その絬果場合によっては制御性 能が劣化する。これに対する対策として電生形制御が 登場する。

電圧形制御に対しては，L型等価回路が適している ことは既に述べたところであるが(5)，過渡等価回路に おいてむそうである。まずL型過濩等価回路を導とう。 図6の T-II 型過渡等価回路においても，励磁りアク タンス (3/2) $L_{m}$ を端子に移すための誤差は小さいの で，実用上さしつかえないとする。とのとき誤差は图 3 のT型回路加ら 型回路を得るよりは少ない。この ように考えて，因7のL型過渡等価回路が得られる。 この回路の回路方程式は下記之なる。 




図 7 L 型過渡等洒回路

Fig. 7. L type transient equivalent circuit.

$$
\begin{aligned}
& v_{1}=\frac{3}{2} L_{m} \alpha p i_{0}^{\prime \prime} \\
& v_{1}=-\left\{R_{1}+\frac{3}{2} L_{m}\left(\alpha^{2}-\alpha\right) p+l_{2} \alpha^{2} p\right. \\
& \left.+R_{2} \alpha^{2}\right\} i_{2}^{\prime \prime}-e^{\prime}
\end{aligned}
$$

ここに，e は(12)式の速度起電力であり， $\alpha$ は(14)式 で与艺られる $\left(i 2^{\prime} \rightarrow i 2^{\prime \prime}\right.$ とする)。

(19)，(20) 式による電圧形制御において，(19) 式中 の厉磁電流 20 亿過渡見象発生しないような制御を 行なうことは容易である。一次電圧 $v_{1}$ を，大きさは

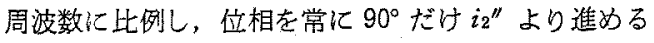

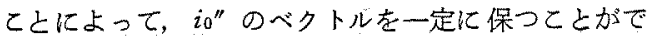
きる。このとき (20) 式は下記となる。

$$
v_{1}=j \omega \frac{3}{2} L_{m} \alpha i_{0}^{\prime \prime}
$$

$$
\begin{aligned}
i_{1}=i_{0}^{\prime \prime}-i_{2}^{\prime \prime} & (12),(20) \text { 式に代入して } \\
v_{1}= & j \omega_{m} \frac{3}{2} L_{m} \alpha i_{0}^{\prime}-\left[R_{1}+\alpha^{2} R_{2}\right. \\
& +\left\{\alpha^{2} l_{2}+\frac{3}{2} L_{m}\left(\alpha^{2}-\alpha\right)\right\} \\
& \left.\times\left(p-j \omega_{m}\right)\right] i_{2}^{\prime \prime} \ldots \ldots \ldots \ldots \ldots \ldots
\end{aligned}
$$

この式の第1項は(21)式より

$$
j \omega_{m} \frac{3}{2} L_{m} \alpha i_{0}{ }^{\prime \prime}=\frac{\omega_{m}}{\omega} v_{1}=(1-s) v_{1}
$$

となって, (22)式は

$$
\begin{aligned}
s v_{1}= & -\left[R_{1}+\alpha^{2} R_{2}+\left\{\alpha^{2} l_{2}+\frac{3}{2} L_{m}\right.\right. \\
& \left.\left.\times\left(\alpha^{2}-\alpha\right)\right\}\left(p-j \omega_{m}\right)\right] i_{2}^{\prime \prime} \ldots \ldots .
\end{aligned}
$$

となる。この特性根は1個て

$$
p=-\frac{R_{1}+\alpha^{2} R_{2}}{\alpha^{2} l_{2}+\frac{3}{2} L_{m}\left(\alpha^{2}-\alpha\right)}+j \omega_{m}
$$

となる。この減旁時定数を第 5 章の表 1 の例について 計算すると,

$$
T_{v}=\frac{\alpha^{2} l_{2}+\frac{3}{2} L_{m}\left(\alpha^{2}-\alpha\right)}{R_{1}+\alpha^{2} R_{2}}=0.0023 \mathrm{~s}
$$

となって，転速に無関係て，極めて小さい。電流形制 御の時定数は $T_{c}=0.101 \mathrm{~s}$ であったが(6)，てれよりあ はるか心小さくて，過渡現象加発生してす実用上さし つがないはどに小さい。との事春は電壬形制御が実 用上非常に有利であることを示すちのである。

\section{5. 過渡トルクの計算}

第 2 章で説明したように，電流形制御を理論通りに 行なえば，トルク応答には図2に示すように，時間荤 れはない。これは電流形制御の大きな特長である。し かしながら温度変化や一次漏れインダクタンスのため に，理論通りの電流形制御は実行できない。その場合 トルク制御の応答に過渡現象が発生することは避けら れないので，これを計算してみよう。

図50 T-I 型過渡等価回路について, 一次電流を

$$
i_{1}=\sqrt{2} I_{1} e^{j\left(\omega t+\varphi_{1}\right)}
$$

とすると，励䂿要流の応答は(17) 式で与えられ，乙れ を書き換えて，下式を得る。

$$
i_{0}{ }^{\prime}=\frac{R_{2}^{\prime}}{Z_{2}{ }^{\prime}} \sqrt{2} I_{1} e^{j\left(\omega t+\varphi_{1}-\theta_{0}\right)}+\Delta I_{0} e^{\delta t} \ldots
$$

ここに, $Z_{2^{\prime}} e^{j \theta 0}$ は二次のメッシュインピーダンス, $\Delta I_{0}$ は (17) 式の第 2 ，第3 項の係数の差である。二次 電流は

$$
\begin{aligned}
i_{2}{ }^{\prime}= & i_{0}{ }^{\prime}-i_{1}=-\frac{s \omega \frac{3}{2} L_{m} \alpha}{Z_{2}^{\prime}} V \overline{2} I_{1} e^{j\left(\omega t+\varphi_{1}+\theta_{2}\right)} \\
& +\left|\Delta I_{0}\right| e^{-\lambda t} e^{j\left(\omega m+\varphi_{3}\right)} \ldots \ldots \ldots \ldots \ldots(27)
\end{aligned}
$$

ここに, $\theta_{2}=(\pi / 2)-\theta_{0}, \Delta I_{0}=\left|\Delta I_{0}\right| e^{j \phi_{3}}$ であり, $\lambda$ は (4) 式で与えられる。

一相当りの僢時トルクは，Pを極数として,

$$
T_{1}=\frac{1}{\omega_{m}} \frac{P}{2} \operatorname{real}\left[e^{\prime}\right] \operatorname{real}\left[i_{2}^{\prime}\right]
$$

となる。 $e^{\prime}$ は (12) 式の速度起電力で，乙の奏数部は

$$
\begin{aligned}
\operatorname{real}\left[e^{\prime}\right]= & \omega_{m} \frac{3}{2} L_{m} \alpha \sqrt{2} I_{1} \sin \left(\omega t+\varphi_{1}\right) \\
& -\omega_{m}\left(l_{2} \alpha^{2}+\frac{3}{2} L_{m} \alpha^{2}\right) \\
& \times \frac{s \omega(3 / 2) L_{m} \alpha}{Z_{2}^{\prime}} \sqrt{2} I_{1} \\
& \times \sin \left(\omega t+\varphi_{1}+\theta_{2}\right) \\
& \left.+\left|\Delta I_{2}\right| e^{-\lambda t} \sin \left(\omega_{m} t+\varphi_{3}\right)\right\}
\end{aligned}
$$

二次電流の笑数部は

$$
\operatorname{real}\left[i_{2}^{\prime}\right]=-\frac{s \omega \frac{3}{2} L_{m} \alpha}{Z_{2^{\prime}}} \sqrt{2} I_{1}
$$






図 8 電流形, 電王形トルク制御の応答

Fig. 8. Response curves of torque control for current-type control and voltage-type control.

$$
\begin{aligned}
& \times \cos \left(\omega t+\varphi_{1}+\theta_{2}\right) \\
& +\left|\Delta I_{0}\right| e^{-\lambda t} \cos \left(\omega_{m} t+\phi_{3}\right)
\end{aligned}
$$

(28) 式の一相当りのトルクは，(29)，(30)式の積とし て 6 項古るが，三相全体のトルク $T_{3}$ は，三相回路の 対称性を考えると，下記のごよく2 項のみとなる。

$$
\begin{aligned}
T_{3}= & \frac{1}{\omega_{m}} \frac{P}{2}\left[\frac{s \omega\left(\frac{3}{2} L_{m} \alpha\right)^{2}}{Z_{2}{ }^{2}} I_{1}^{2} \sin \theta_{2}\right. \\
& -\frac{3}{2} L_{m} \alpha \frac{I_{1}}{\sqrt{2}}\left|\Delta I_{0}\right| e^{-\lambda t} \\
& \left.\times \sin \left(s \omega t+\varphi_{1}-\varphi_{3}\right)\right] \ldots \ldots \ldots \ldots . . .
\end{aligned}
$$

第 1 項は定常トルクで一定であり，第 2 項は過渡トル クである。

表1のモータを，無角荷で運転中に，定格トルク (24.6N-m) の 2.39 倍のトルク指令（すべり $=0.042$ $\times 2.39=0.1$ 亿相当）が来たときの出力トルクは図 8 に示すように，理諭通りに電流形制御を行なうと(31) 式で $\Delta I_{0}=0$ となるので，時間遅れがなくトルク指令 值の $58.5 \mathrm{~N}-\mathrm{m}$ となる。

しかし回転子温度が上って, 二次抵抗 $R_{2}\left(75^{\circ} \mathrm{C}\right.$ 相 当) が $1.26 R_{2}\left(150^{\circ} \mathrm{C}\right.$ 相当)になったとすると, 電流 形制御に諤差を生じて，トルクの定常値は $70.1 \mathrm{~N}-\mathrm{m}$ となって，20\% だけ指令值より高くなり，この定常 值に静定する間の過渡現象の隇衰時定数は 0.101 悡で あって，時闃遅れが大きい。第 4 章の電壬形制剗によ ると, $R_{2}$ が $1.26 R_{2}$ になったとき, 出力トルクの定 常値が $48.6 \mathrm{~N}-\mathrm{m}$ となって，指令值より $17 \%$ 低下す

表 1 モータ定数

Table 1. Motor constant.

るが，過渡トルクの減衰時定数は $3 \mathrm{~ms}$ 弱之極めて小さ いので，実用上ステップ状の応答となる。この例加ら も䉓圧形制御のほうが，実用上有利であるといえる。 先の諭文 ${ }^{(5)}$ で示したように，制御回路が簡単になるこ 亡も，電瓜形制御の長所である。

\section{6. 結言}

譑導機について新たに開発した過渡等価回路を用い て，過渡現象を解析して，過渡䍐象の発生しない電流 形制御の条件を定めた。これによって時間遲れのない 制御か理論上は可能であることを示した。しかし電流 形制御を理諭通りに実行することは困鹳であるので， 過海現象が発生し，速応制御の妨となるととを示し た。電玨形制御の過樭現象を解析して，時間荤れが極 めて少なく，実用的であるととを示した。以上は磁界 加速法制御に関する重要な結論であると考える。

院生の野中表一君の協力に対し謝意を表する。 (昭和 57 年 8 月 30 日受付，同 58 年 1 月 24 日再受付)

\section{文 献}

（1）山村・安井：「誘洎機の過渡トルク」䉓学誌 75,493 (昭 30 -5)

（2）猪狩：電気機械理脸 130 (昭 52) コロナ社

(3) Adkin, Harley: The General Theory of AC Machines Chagman \& Hall, London, 58 (1975)

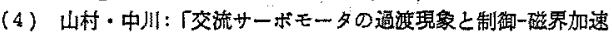

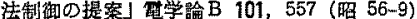

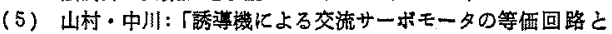

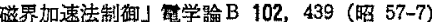

（6）山村・革・中川：「速応サーボモータとしての誘䢘織の等価 回路」電学鍮 B 103，133 (昭 58-2)

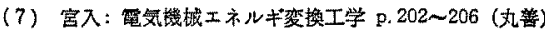

\section{付 録}

I . (17)，(18) 式が T-I 型定常回路に適用できるす のであることを示そう。 $\alpha=(3 / 2) L_{m}\left(\left(l_{2}+(3 / 2) L_{m}\right) て ゙\right.$ あるので,

$$
\begin{aligned}
& I_{0}=\frac{R_{2}}{R_{2}+j s \omega\left(l_{2}+\frac{3}{2} L_{m}\right)} I_{1} \\
& =\frac{\alpha^{2} R_{2}}{\alpha^{2} R_{2}+j s \omega \alpha^{2}\left(l_{2}+\frac{3}{2} L_{m}\right)} I_{1} \\
& =\frac{\alpha^{2} R_{2}}{\alpha^{2} R_{2}+j s \omega \alpha \frac{3}{2} L_{m}} I_{1} \\
& =\frac{\alpha^{2} R_{2} / s}{\frac{\alpha^{2} R_{2}}{s}+j \alpha x_{m}} I_{1}
\end{aligned}
$$

この式は T-I 型定常等価回路に相当する回路方程式 


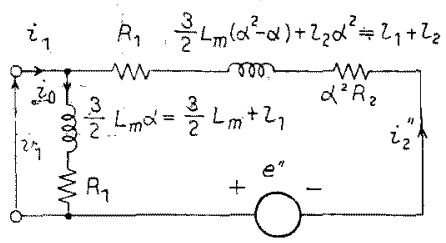

付图 1 変形L型過渡等価回路

app. Fig. 1. Varied L type transient equivalent circuit.

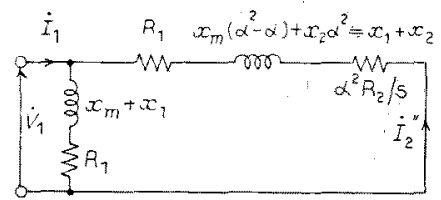

付园 2 変形L型定常等洒回路

app. Fig. 2. Varied L type steady state equivalent circuit.

である。

II. 電死形制御を実行する場合に图 7 のL型回路で 住閶題加ある。電源周波数が露となったときに，励磁 電流が不定となる。この点を是正するために，付図 1 に示すように，励磁回路に $R_{1}$ を直列に入れるとととし て，とれを変形L型過渡等価回路と名付けることにす る。付図 2 は変形L 型定常等価回路である。これは図 6 の非対称 T-II 型回路で, $l_{1}$ が $(3 / 2) L_{m}$ 己 $l_{2}$ との雨 方に直列に入っているととに相当するが，これは理論

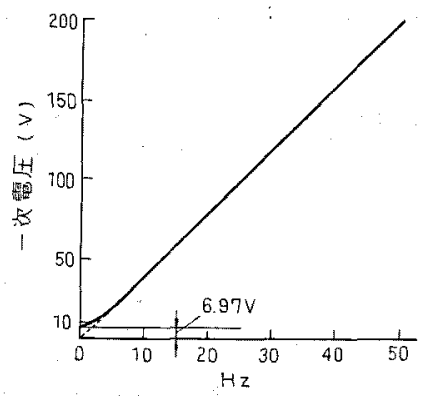

付图 3 電圧形制御の一次電圧対周波数曲線 app. Fig. 3. Voltage-frequency curve for voltage-type control.

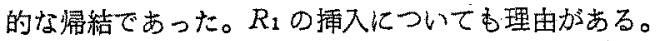
無真荷電流の值加図 $70 \mathrm{~L}$ 型回路よりあ, 変形 $\mathrm{L}$ 型回 路のほうがより正しいるのとなる。変形工型回路では (21)式仕下郡となる。

$$
v_{1}=\left(j \omega \frac{3}{2} L_{m} \alpha+R_{1}\right) i_{0}^{\prime \prime}
$$

この式によって，一次電圧の大きさと電源周波数との 関係を示すと，付因 3 となる。周波数が非常に低い範 国で淔線から少しずれるにすぎない。周波数が零の上 きに $V_{1}=6.97 \mathrm{~V}$ とる。これはモータが停止中にも i。を一定に保守するための電正であって，停止中のモ ータが速応性を失なわないためには必要である。 